\title{
Mechanosensitivity of Embryonic Neurites Promotes Their Directional Extension and Schwann Cells Progenitors Migration
}

\author{
Gonzalo Rosso ${ }^{a, c}$ Peter Young ${ }^{b}$ Victor Shahin ${ }^{a}$ \\ aInstitute of Physiology II, WWU Münster, ${ }^{b}$ Department of Sleep Medicine and Neuromuscular \\ Disorders, Münster; 'Biotechnology Center of the TU Dresden, Dresden, Germany
}

\section{Key Words}

Peripheral nervous system • Schwann cells • Neurites - Mechanosensitivity • Regeneration medicine

\begin{abstract}
Background/Aims: Migration of Schwann cells (SCs) progenitors and neurite outgrowth from embryonic dorsal root ganglions (DRGs) are two central events during the development of the peripheral nervous system (PNS). How these two enthralling events preceding myelination are promoted is of great relevance from basic research and clinical aspects alike. Recent evidence demonstrates that biophysical cues (extracellular matrix stiffness) and biochemical signaling act in concert to regulate PNS myelination. Microenvironment stiffness of SCs progenitors and embryonic neurites dynamically changes during development. Methods: DRG explants were isolated from day 12.5 to 13.5 mice embryos and plated on laminin-coated substrates with varied stiffness values. After 4 days in culture and immunostaining with specific markers, neurite outgrowth pattern, SCs progenitors migration, and growth cone shape and advance were analyzed with confocal fluorescence microscopy. Results: We found out that growing substrate stiffness promotes directional neurite outgrowth, SCs progenitors migration, growth cone advance and presumably axons fasciculation. Conclusions: DRG explants are in vitro models for the research of PNS development, myelination and regeneration. Consequently, we conclude the following: Our observations point out the importance of mechanosensitivity for the PNS. At the same time, they prompt the investigation of the important yet unclear links between PNS biomechanics and inherited neuropathies with myelination disorders such as Charcot-Marie-Tooth $1 \mathrm{~A}$ and hereditary neuropathy with liability to pressure palsies. Finally, they encourage the consideration of mechanosensitivity in bioengineering of scaffolds to aid nerve regeneration after injury.
\end{abstract}




\section{Cellular Physiology Cell Physiol Biochem 2017;44:1263-1270 \begin{tabular}{ll|l} 
and Biochemistry Published online: November 29, 2017 & $\begin{array}{l}\text { (c) } 2017 \text { The Author(s). Published by S. Karger AG, Basel } \\
\text { www.karger.com/cpb }\end{array}$
\end{tabular} \\ Rosso et al.: Mechanosensitivity of Embryonic DRGs}

\section{Introduction}

Cells exert forces on their microenvironment, and at the same time sense the stiffness of the extracellular matrix (ECM) [1]. This so called mechanosensitivity is crucial for central nervous system development and repair [2], and recent studies demonstrate that isolated peripheral nervous system (PNS) neurons and Schwann cells (SCs) are mechanosensitive $[3,4]$. SCs perform numerous tasks crucial for PNS development, maintenance, survival, protection and regeneration [5]. Their interaction with neurons is biochemical and mechanical $[5,6]$. During development, SCs originate from neural crest in dorsal root ganglions (DRGs) and migrate along bundles of outgrowing axons from the spinal cord to the periphery [5]. The mechanisms underlying SCs migration from DRGs remain heatedly discussed [7]. SCs gradually secrete a basal lamina (ECM), which mediates their physiological roles and biochemical cross-talk with extending neurites [5]. The gradual deposition of ECM dynamically increases the stiffness around SCs and axons during PNS development. Substrate stiffness strongly modulates gene expression in purified SCs [8] and we have shown that morphology and motility of the same cells are highly substrate stiffness-sensitive [4]. Hence, the question is pressing as to whether ECM stiffness acts in concert with biochemical signaling to promote SCs progenitors migration. Like SCs migration, directionality of neurite extension and growth cone guidance remain inexplicit [2]. Mechanosensitive active pulling forces at the leading growth cones generate axonal tension and promote axonal growth [9]. Recent evidence demonstrates that PNS myelination is highly sensitive to substrate stiffness [6]; Yap and Taz, effectors of the Hippo pathway, which are known to integrate chemical and mechanical signals in cells [10], control the mechanosensitive PNS myelination [6, 11].

\section{Materials and Methods}

Generation of laminin-coated polyacrylamide substrates with different stiffness

Polyacrylamide (PA) precursor gels were produced from $40 \%$ (w/v) acrylamide (Sigma-Aldrich), 2 $\%(\mathrm{w} / \mathrm{v}$ ) bis-acrylamide (Bio-Rad Laboratories) and $97 \%(\mathrm{w} / \mathrm{v}$ ) and $\mathrm{N}$-Hydroxyethyl acrylamide (SigmaAldrich) stock solutions to generate substrates with distinct stiffness values (elastic moduli: $1 \mathrm{kPa}, 10 \mathrm{kPa}$ and $20 \mathrm{kPa}$ ), which were corroborated by indentation measurements using atomic force microscopy. First, $25 \mathrm{~mm}$ glass coverslips were cleaned with $70 \%$ ethanol and treated with $0.1 \%$ sodium hydroxide $(\mathrm{NaOH})$ to make the surface hydrophobic. Then coverslips were incubated for 3 minutes with (3-Aminopropyl) trimethoxysilane (APTMS, Sigma-Aldrich) to functionalize the glass surface. Subsequently, pretreated coverslips were coated for 30 minutes with $0.5 \%$ glutaraldehyde. PA precursor mix containing $500 \mu \mathrm{l} 40 \%$ acrylamide (Sigma-Aldrich), $65 \mu \mathrm{l}$ 100\% hydroxyacrylamide (Sigma-Aldrich) and $250 \mu \mathrm{l}$ 2\% bis-acrylamide (Bio-Rad) was shortly degassed in vacuum desiccator. Gel polymerization was initiated by adding $0.1 \%$ $\mathrm{w} / \mathrm{v}$ Ammonium-Persulfate (Sigma-Aldrich) and $0.1 \% \mathrm{w} / \mathrm{v}$ tetramethylethylenediamine (TEMED, Bio-Rad Laboratories) to the PA precursor mix. A drop of polymerizing PA mix was added to the $25 \mathrm{~mm}$ coverslips and immediately covered with water-repellent solution RainX ${ }^{\circledR}$ (RainX Co, USA) pre-treated (20 mm) glass coverslips in order to produce approximately 30 micrometer thick gel substrates. After PA polymerization (approx. 30 minutes) the gels were placed in 6-well culture plate containing phosphate buffer solution (PBS) and the $20 \mathrm{~mm}$ coverslips were removed. Gels were rinsed with PBS several times to remove the non-polymerized acrylamide. PA gels sterilization was carried out exposing the gels to UV light for $\sim 10$ minutes. Surface coating to promote Schwann cell adhesion was induced incubating PA gels with poly-Dlysine (Sigma-Aldrich) overnight at $4^{\circ} \mathrm{C}$. The next day gels were washed and incubated for 2 hours at room temperature with $10 \mu \mathrm{g} / \mathrm{mL}$ laminin (Sigma-Aldrich). PA gels were covered with cell culture medium and allowed to equilibrate inside incubator at $37^{\circ} \mathrm{C}$ for 1 hour before seeding the cells.

\section{Isolation and culture of embryonic DRG explants}

Animal studies and procedures were conducted in accordance with the European Convention for Animal Care and Ethical Use of Laboratory Animals and have been approved by the local governmental authorities (State Office for Nature, Environment and Consumer Protection, North Rhine-Westphalia, Germany; File 


\section{Cellular Physiology Cell Physiol Biochem 2017;44:1263-1270 \begin{tabular}{l|l|l} 
and Biochemistry Published onlIne: November 29, 2017 & $\begin{array}{l}\text { (c) } 2017 \text { The Author(s). Published by S. Karger AG, Basel } \\
\text { www.karger.com/cpb }\end{array}$ \\
\hline
\end{tabular} \\ Rosso et al.: Mechanosensitivity of Embryonic DRGs}

reference 84- 02.05.20.12.146). DRG explants were dissected from embryonic mice as described in our recent publication [4]. Basically, DRGs explants were isolated from day 12.5 to 13.5 C57BL6/J mice embryos and plated on PA substrates which were previously coated with poly-D-Lysine (Sigma-Aldrich) and $10 \mu \mathrm{g} /$ mL laminin (Sigma-Aldrich). DRG explants were maintained in Neurobasal medium (Invitrogen) containing $20 \mu \mathrm{L} / \mathrm{mL}$ B27 supplement 50X (Gibco), $10 \mu \mathrm{L} / \mathrm{mL}$ Antibiotic-Antimycotic, $2 \mathrm{mM}$ Glutamax (Invitrogen) and $0.01 \mu \mathrm{g} / \mathrm{mL}$ nerve growth factor (NGF, Invitrogen) at $37^{\circ} \mathrm{C}$ and $5 \% \mathrm{CO}_{2}$.

\section{Analysis of SCs migration from embryonic DRG explants}

After 4 days in culture, DRG co-cultures of axons and SCs were fixed with 4\% paraformaldehyde (Sigma-Aldrich) for 2 hours at $4^{\circ} \mathrm{C}$ and washed with PHEM buffer ( $5 \mathrm{mM}$ Pipes, $60 \mathrm{mM}$ HEPES, $10 \mathrm{mM}$ EGTA and $2 \mathrm{mM} \mathrm{MgSO}_{4}$, pH 7.0 with $\mathrm{KOH}$; all components from Sigma-Aldrich). Co-cultures were prepared for immunocytochemistry by incubating DRG explants in blocking solution (PHEM + 5\% normal goat serum) followed by membrane permeabilization with $0.1 \%$ Triton X-100 for 20 minutes. For axons and SCs staining samples were incubated overnight at $4{ }^{\circ} \mathrm{C}$ with primary antibodies: monoclonal class III beta-tubulin antibody 1:1000 (Covance) and anti-S100 (1:500, Dako), respectively. Secondary antibodies Alexa-488 and Alexa-546 (Invitrogen) were incubated overnight at $4^{\circ} \mathrm{C}$. For image acquisition a Leica TCS SP8 confocal microscope (Leica Microsystems, Wetzlar, Germany) equipped with 488, 543 and $633 \mathrm{~nm}$ laser lines and 10X objective was used. Cell nuclei were stained with DAPI contained in mounting media (Dako). For quantification of SCs migration on embryonic DRG explant we utilised Fiji ImageJ (v1.50e) software. Migration distances of SCs (S100-positive) were determined by measuring the total covered distance from the border of DRG exit to the final captured positions of SCs on the axons. Data analysis and graph production was carried out using Origin Pro 8.0 software (Origin Lab Corporation, Northampton, MA, USA).

\section{Neurites orientation analysis}

DRG explants cultured over laminin-coated substrates with distinct elastic moduli (1 kPa, $10 \mathrm{kPa}, 20$ $\mathrm{kPa}$ and glass) were stained using a $\beta$-tubulin antibody to visualize axons. Images of approximately 100.000 $\mu \mathrm{m}^{2}$ around DRG explant borders were recorded and imported to Fiji. The axon orientation analysis was carried out with the ImageJ plug-in OrientationJ [12] using the dominant orientation option. The parameter orientation coherency given by this software enables the determination of the orientation isotropy of the structures within the image. Hence, the orientation isotropy in the image ranges from zero (isotropic areas with no preferential orientation) to one (highly oriented structures).

\section{Growth cone morphology}

For the analysis of growth cone morphologies, embryonic DRG neurons were stained for a specific membrane protein (Neuregulin-1 (NRG-1) type III, Abcam). Fluorescent images were obtained with confocal microscopy and the growth cone spreading areas were measured with ImageJ software (NIH, USA). Spreading area was determined by outlining the entire surface of the growth cone (starting from the neck position). Growth cone average areas on the different substrates and glass were analyzed and compared with Origin Pro 8.0 software (Origin Lab Corporation, Northampton, MA, USA).

\section{Statistical analysis}

Data are presented as mean values \pm standard error of the mean (SEM). Data were tested for normal distribution. Depending on data distribution, parametric (Student's t-test) or non-parametric (MannWhitney test) were utilized. ANOVA tests were used when more than two groups were compared. Results were considered as statistically significant at the probability level $\mathrm{p}<0.05\left(^{*}\right)$.

\section{Results}

Effect of substrate-stiffness on SCs progenitors migration from DRG explants

After 4 days in culture over laminin-coated substrates with varied stiffness values, migration distances of SCs progenitors from embryonic DRG explants were measured (Fig. 1). In repeated experiments, 180, 126, 266 and 217 SCs were analyzed on $1 \mathrm{kPa}, 10 \mathrm{kPa}, 20$ $\mathrm{kPa}$ and glass, respectively. SCs migration distances (mean \pm SEM; N=10 DRG explants in 


\section{Cellular Physiology \begin{tabular}{ll|l} 
and Biochemistry Published onlıne: November 29, 2017 & $\begin{array}{l}\text { (c) } 2017 \text { The Author(s). Published by S. Karger AG, Basel } \\
\text { www.karger.com/cpb }\end{array}$
\end{tabular}}

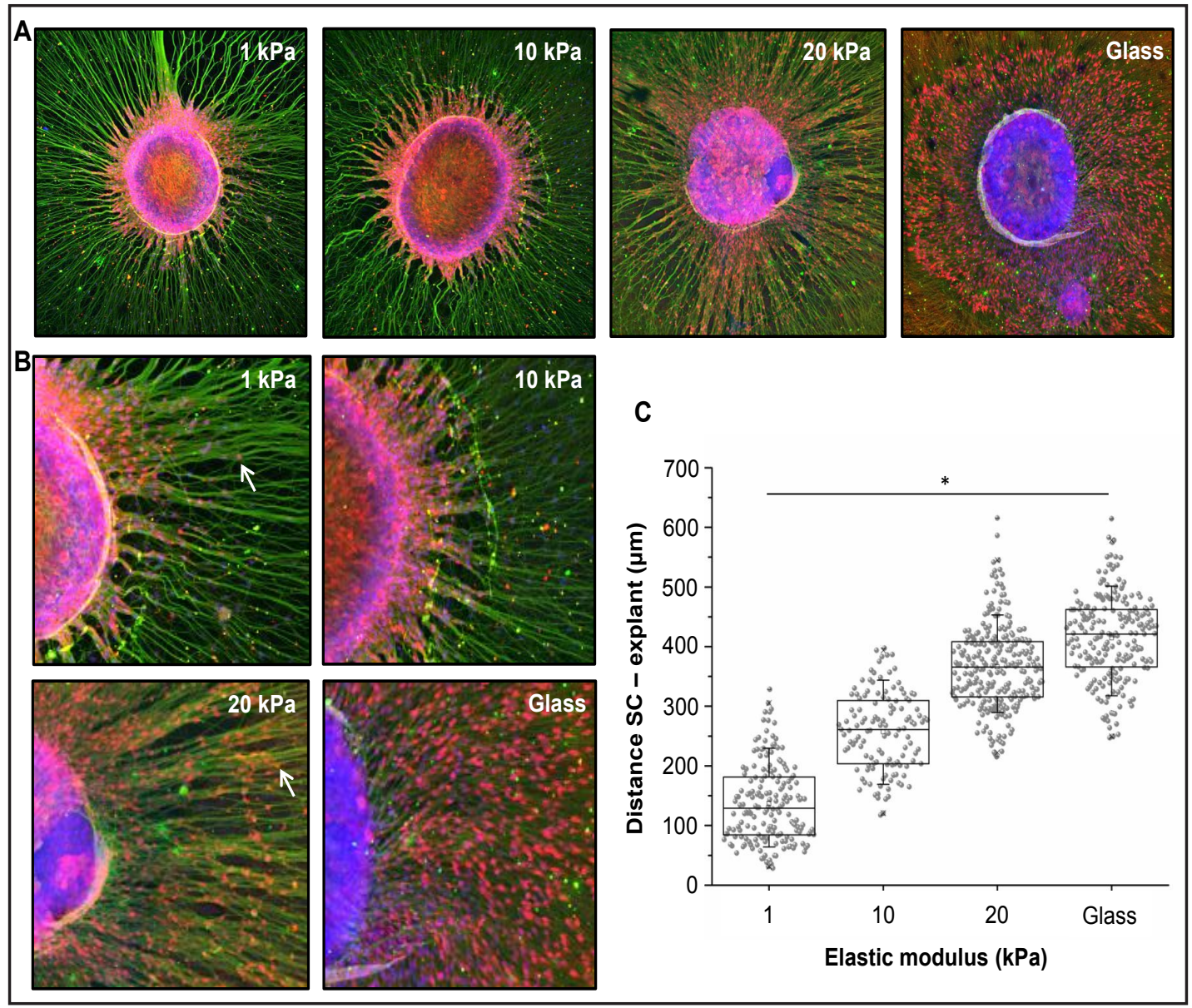

Fig. 1. Influence of substrate stiffness on SCs progenitors migration from embryonic DRGs. (A) Representative confocal microscopy images of embryonic DRG explants (E12.5 - 13.5) after 4 days over laminin-coated substrates with different stiffnesses (elastic moduli: $1 \mathrm{kPa}, 10 \mathrm{kPa}, 20 \mathrm{kPa}$ and glass). SCs cells (red), neurites (green) and nuclei (blue) were stained with anti-S100 antibody, neuronal anti-tubulin antibody and DAPI, respectively. (B) Insets from the images in (A). Individual migrating SCs are indicated by arrows. (C) SCs migration distance over outgrowing neurites correlates with the substrate stiffness. $(*$ ) indicates significant statistical differences ( $p<0.05$, ANOVA). Images are $1000 \mu \mathrm{m}$ each.

each condition) were $148.1 \pm 5.3 \mu \mathrm{m}, 264 \pm 9.2 \mu \mathrm{m}, 343 \pm 6.5 \mu \mathrm{m}$ and $432 \pm 9.0 \mu \mathrm{m}$ on $1 \mathrm{kPa}$, $10 \mathrm{kPa}, 20 \mathrm{kPa}$ and glass, respectively.

\section{Effect of substrate-stiffness on neurite outgrowth shape and directionality}

In parallel to SCs migration we studied the orientation pattern of extending embryonic DRG neurons after 4 days in culture, in response to substrate stiffness (Fig. 2). Neurite outgrowth pattern is strongly wavy on $1 \mathrm{kPa}$ and waviness is reduced on $10 \mathrm{kPa}$. In contrast, neurite outgrowth pattern on $20 \mathrm{kPa}$ is rather straight and neurites form outstretched bundles aligned in parallel orientation to each other over long distances. Besides, neurites fasciculation tendency apparently correlates with substrate stiffness. To quantify the directionality of neurite outgrowth we used an orientation analysis algorithm based on the orientation coherence of fluorescently labelled structures in the recorded images [12]. The parameter orientation coherence enables the determination of the orientation isotropy of the structures within the image [12]. The orientation isotropy ranges from zero (isotropic areas with no preferential orientation) to one (highly oriented structures) [12]. Ten DRGs were tested in each condition. $20 \mathrm{kPa}$ substrates promote the growing of oriented neurites $(0.549 \pm 0.06)$, whereas $10 \mathrm{kPa}(0.430 \pm 0.05)$ and $1 \mathrm{kPa}(0.348 \pm 0.06)$ substrates promote 


\section{Cellular Physiology Cell Physiol Biochem 2017;44:1263-1270 \begin{tabular}{l|l|l} 
and BOI: 10.1159/000485485 & $\begin{array}{l}\text { C } 2017 \text { The Author(s). Published by S. Karger AG, Basel } \\
\text { www.karger.com/cpb }\end{array}$
\end{tabular} Rosso et al.: Mechanosensitivity of Embryonic DRGs}

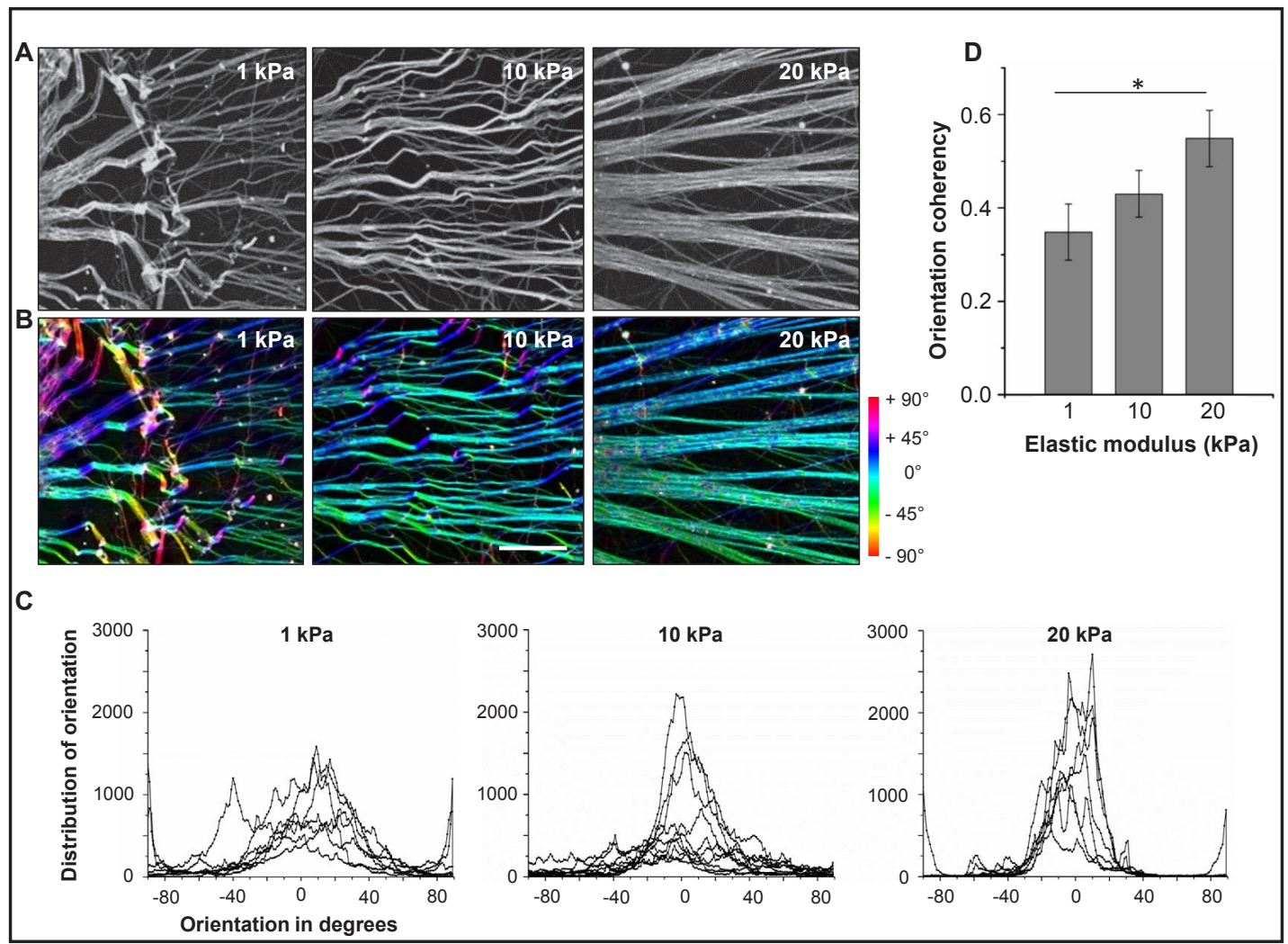

Fig. 2. Influence of substrate stiffness on the directionality of neurites outgrowth from embryonic DRGs. (A) Representative confocal microscopy images of embryonic DRG explants over laminin-coated substrates with elastic moduli $1 \mathrm{kPa}, 10 \mathrm{kPa}$ and $20 \mathrm{kPa}$. DRG neurites are fluorescently labelled with $\beta$-tubulin (grey). (B) Color-coded maps showing neurites orientation angles in (A). (C) Histograms of local orientation angles. (D) Orientation coherency analysis (directionality). $\left(^{*}\right)$ indicates significant statistical differences $(\mathrm{p}<0.05$, Mann-Whitney test). Images are $400 \mu \mathrm{m}$ each.

axonal outgrowth in a less oriented isotropic shape. We also analyzed the local directionality angles of DRG neurites from color-coded confocal microscopy images [12]. Representative color-coded maps showing local directionality angles of DRG neurites and the corresponding histograms are shown in Fig. 2B,C. The range of possible angle values is between $-90^{\circ}$ and $90^{\circ}$. The distribution range of angle orientations on $10 \mathrm{kPa}$ and $20 \mathrm{kPa}$ substrates shows that peaks are centered around $-20^{\circ}$ and $+20^{\circ}$. In contrast, on $1 \mathrm{kPa}$ the directionality pattern of neurite angles has a widespread distribution.

\section{Effect of substrate-stiffness on growth cone shape}

We investigated the effect of substrate stiffness on growth cone morphology in 10 DRGs in each experimental condition. Confocal microscopy images of fluorescently labelled DRG growth cones on laminin-coated substrates are shown in Fig. 3A. Cones spreading areas significantly increased from $75.8 \pm 4 \mu \mathrm{m}^{2}$ on $1 \mathrm{kPa}$ ( $\mathrm{n}=88$ cones) to $189.5 \pm 20 \mu \mathrm{m}^{2}$ on 20 $\mathrm{kPa}(\mathrm{n}=55)$. Intriguingly, no significant differences were observed between $1 \mathrm{kPa}, 10 \mathrm{kPa}$ $\left(82.8 \pm 5 \mu \mathrm{m}^{2}, \mathrm{n}=72\right)$ and glass $\left(65.1 \pm 4 \mu \mathrm{m}^{2}, \mathrm{n}=46\right)$. In addition to the increased area, growth cones on $20 \mathrm{kPa}$ substrates show more filopodia compared to $1 \mathrm{kPa}, 10 \mathrm{kPa}$ and glass.

\section{Discussion}

We have recently shown that the average elastic Yong's modulus of mature myelinated nerve fibers from mice is $\sim 20 \mathrm{kPa}$ [13]. Here, embryonic DRG explants were exposed to 


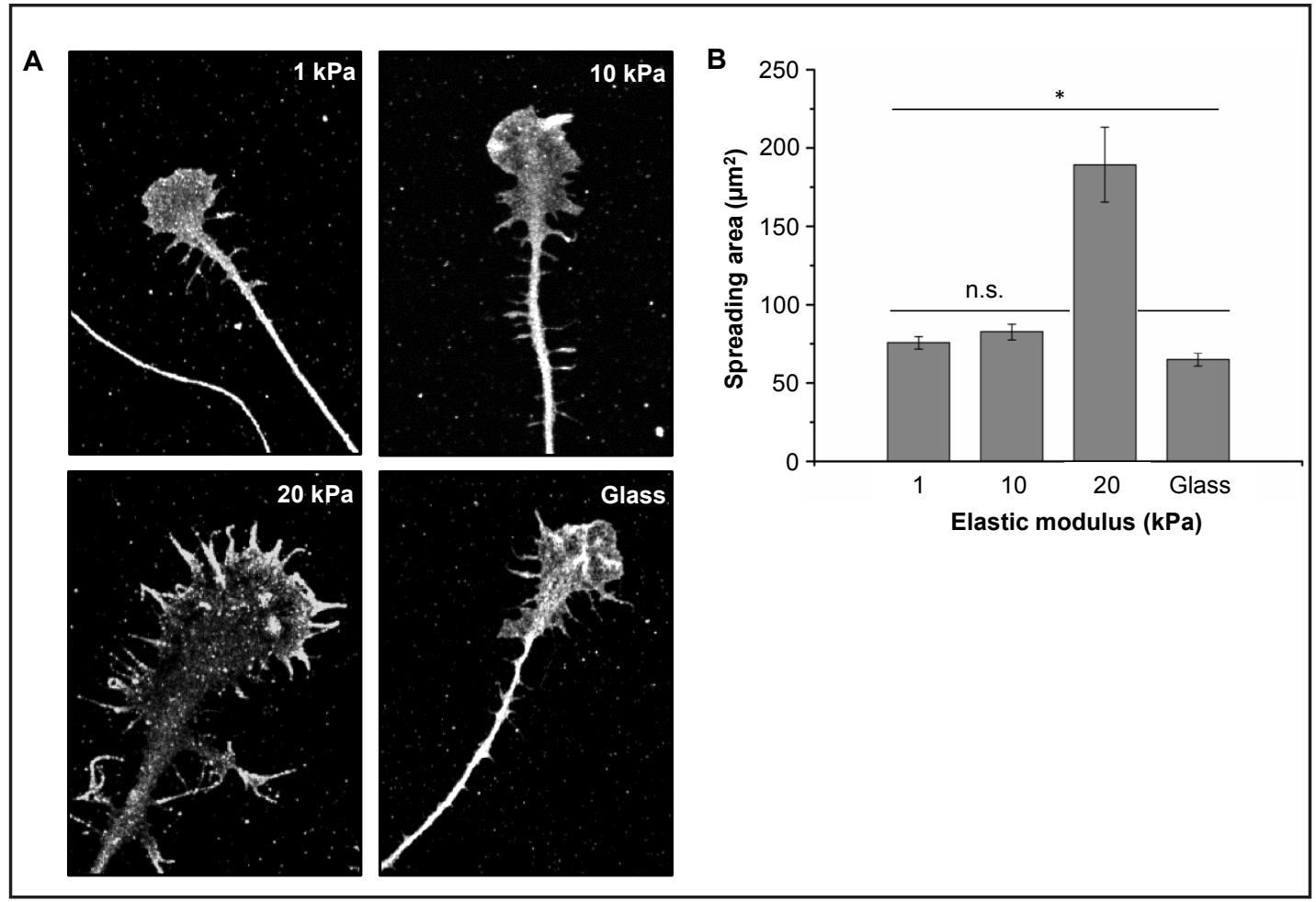

Fig. 3. Influence of substrate stiffness on the morphology of embryonic DRG growth cones. (A) Representative confocal microscopy images of membrane labelled (NRG-1 type III, gray) DRG growth cones over laminincoated substrates with different stiffnesses (elastic moduli: $1 \mathrm{kPa}, 10 \mathrm{kPa}, 20 \mathrm{kPa}$ and glass). (B) Spreading areas of DRG neurons growth cones depending on substrate stiffness. $\left({ }^{*}\right)$ indicates significant statistical differences ( $\mathrm{p}<0.05$, Mann-Whitney test) while n.s. stands for not significant. Images are $45 \mu \mathrm{m}$ each.

substrates with elastic moduli of $1 \mathrm{kPa}, 10 \mathrm{kPa}$ and $20 \mathrm{kPa}$, referred to as soft, medium and hard, respectively. The substrates were coated with laminin, a major constituent of SCs basal lamina and a key mediator of SCs actions [14]. The selected stiffness range corresponds to early, intermediate and adult developmental stages, respectively [4]. Putting the observations together: We have previously shown that outgrowth length of neurites from embryonic DRG explants is substrate stiffness-sensitive [4]. Here we show that also extension pattern, directionality and presumably fasciculation of embryonic DRG neurites strongly depend on substrate stiffness. Consistently, recent findings demonstrate that axons growing out of a retinal ganglion cell explant increase defasciculation and aberrant growth on soft substrates, while on stiff substrates axons grow in paralleled straight orientation [15]. We speculate that traction forces and the expression levels of cell-ECM adhesion molecules in axons correlates with the substrate stiffness. We also envisage that hampered biomechanical communication between neurites and the ECM is involved in pathogenesis of the inherited neurological disorders Charcot-Marie-Tooth 1A (CMT1A) and hereditary neuropathy with liability to pressure pulse (HNPP). CMT1A and HNPP are closely associated with biomechanical vulnerability entailing nerves which become prone to action potential conduction block and motoric disorders [16-18]. Growth cone-ECM interactions are important for force generation, axonal growth and guidance during nervous system development [2]. Traction forces generate tension which increases with increasing substrate stiffness [19]. Consistently, we observe increased interaction between growth cones and substrates with increasing substrates stiffness. Moreover, growth cones mechanosensitivity is highest within a specific range (intermediate to hard) and lowest at soft and too hard (glass). The latter indicates that a specific range of substrate compliance is necessary to allow optimal growth cone-ECM interaction. This proposes biochemical and biophysical cross-talk

\section{KARGER}




\section{Cellular Physiology Cell Physiol Biochem 2017;44:1263-1270 \begin{tabular}{ll|l} 
DOI: 10.1159/000485485 & $\begin{array}{l}\text { O 2017 The Author(s). Published by S. Karger AG, Basel } \\
\text { www.karger.com/cpb }\end{array}$ \\
and Biochemistry Published online: November 29, 2017
\end{tabular}

rather than purely biophysical response that is likely to regulate the expression of proteins (focal adhesions, the cytoskeleton and myosin II) important for the mechanotransduction of neurons [20]. We have previously shown that purified SCs are sensitive to the stiffness of their substrate and that they are motile within a stiffness range [4] which encompasses the stiffness of PNS neurons [21]. In the experimental model of the present work SCs do not interact directly with the substrate in opposite to extending neurites. Therefore, we can imagine that a change in substrate stiffness triggers a biochemical response in neurites which promotes migration of SCs progenitors from DRG explants. A role of Yap/Taz signaling is conceivable as in mechanosensitive PNS myelination [6]. Yap and Taz are expressed in DRG progenitors and glia during DRG development and Yap signaling plays important roles in controlling the expansion of DRG progenitors and glia during development [22]. Hence, mechanosensitivity of outgrowing neurites may act in concert with biochemical signaling to promote migration of SCs progenitors. We assume that mechanosensitivity of SCs is important for their interaction with outgrowing neurites. Recent evidence demonstrate that SCs feel and respond to the stiffness of their substrate, and that mechanosensitivity plays key roles in SCs shape, adhesion, migration, differentiation, gene expression profiles and myelination $[4,6,8,11,23,24]$. This strong impact of mechanosensitivity on SCs plays important roles in the PNS from biomedical and clinical aspects. Migration of SC precursors from embryonic DRGs is a crucial event for the PNS development. Adhesion of Schwann cells to outgrowing neurites is particularly important during the process of radial sorting and axon myelination, supporting the idea that mechanical sensing of axons plays a role during PNS maturation $[3,4]$. This assumption receives some support considering the facts that SCs morphology is highly sensitive to substrate stiffness [4] and that a switch in SCs morphology, in turn, is a prerequisite to adjust their interaction with axons before and after axonal sorting $[25,26]$. All in all, the present brief work intends to highlight the general importance of mechanosensitivity for the PNS without going into details underlying the cross-talk between biochemical and biophysical cues. It sets the stage for follow-up works which will aim at comprehensive research of the cross-talk at the biochemical and molecular level.

\section{Disclosure Statement}

The authors declare no competing or financial interests.

\section{Acknowledgements}

This work was supported by grants from the DFG (SH 167/6-1), Innovative Medical Research (I-SH111511) and Cells-in-Motion Cluster of Excellence (EXC 1003-CIM).

\section{References}

1 Discher DE, Janmey P, Wang YL: Tissue cells feel and respond to the stiffness of their substrate. Science 2005;310:1139-1143.

-2 Franze K, Janmey PA, Guck J: Mechanics in neuronal development and repair. Annu Rev Biomed Eng 2013;15:227-251.

-3 Koch D, Rosoff WJ, Jiang J, Geller HM, Urbach JS: Strength in the periphery: growth cone biomechanics and substrate rigidity response in peripheral and central nervous system neurons. Biophys J 2012;102:452460.

- 4 Rosso G, Liashkovich I, Young P, Rohr D, Shahin V: Schwann cells and neurite outgrowth from embryonic dorsal root ganglions are highly mechanosensitive. Nanomedicine 2017;13:493-501. 


\section{Cellular Physiology Cell Physiol Biochem 2017;44:1263-1270

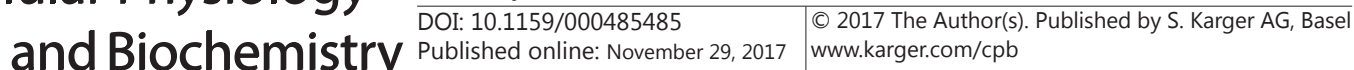

5 Jessen KR, Mirsky R: The origin and development of glial cells in peripheral nerves. Nat Rev Neurosci 2005;6:671-682.

6 Poitelon Y, Lopez-Anido C, Catignas K, Berti C, Palmisano M, Williamson C, Ameroso D, Abiko K, Hwang Y, Gregorieff A, Wrana JL, Asmani M, Zhao R, Sim FJ, Wrabetz L, Svaren J, Feltri ML: YAP and TAZ control peripheral myelination and the expression of laminin receptors in Schwann cells. Nat Neurosci 2016;19:879-887.

7 Heermann S, Schwab MH: Molecular control of Schwann cell migration along peripheral axons: keep moving! Cell Adh Migr 2013;7:18-22.

-8 Gu Y, Ji Y, Zhao Y, Liu Y, Ding F, Gu X, Yang Y: The influence of substrate stiffness on the behavior and functions of Schwann cells in culture. Biomaterials 2012;33:6672-6681.

-9 Betz T, Koch D, Lu YB, Franze K, Kas JA: Growth cones as soft and weak force generators. Proc Natl Acad Sci U S A 2011;108:13420-13425.

10 Dupont S, Morsut L, Aragona M, Enzo E, Giulitti S, Cordenonsi M, Zanconato F, Le DJ, Forcato M, Bicciato S, Elvassore N, Piccolo S: Role of YAP/TAZ in mechanotransduction. Nature 2011;474:179-183.

11 Urbanski MM, Kingsbury L, Moussouros D, Kassim I, Mehjabeen S, Paknejad N, Melendez-Vasquez CV: Myelinating glia differentiation is regulated by extracellular matrix elasticity. Sci Rep 2016;6:33751.

12 Rezakhaniha R, Agianniotis A, Schrauwen JT, Griffa A, Sage D, Bouten CV, van de Vosse FN, Unser M, Stergiopulos N: Experimental investigation of collagen waviness and orientation in the arterial adventitia using confocal laser scanning microscopy. Biomech Model Mechanobiol 2012;11:461-473.

13 Rosso G, Liashkovich I, Gess B, Young P, Kun A, Shahin V: Unravelling crucial biomechanical resilience of myelinated peripheral nerve fibres provided by the Schwann cell basal lamina and PMP22. Sci Rep 2014;4:7286.

14 Colognato H, ffrench-Constant C, Feltri ML: Human diseases reveal novel roles for neural laminins. Trends Neurosci 2005;28:480-486.

15 Koser DE, Thompson AJ, Foster SK, Dwivedy A, Pillai EK, Sheridan GK, Svoboda H, Viana M, Costa LD, Guck J, Holt CE, Franze K: Mechanosensing is critical for axon growth in the developing brain. Nat Neurosci 2016;19:1592-1598.

-16 Bai Y, Zhang X, Katona I, Saporta MA, Shy ME, O’Malley HA, Isom LL, Suter U, Li J: Conduction block in PMP22 deficiency. J Neurosci 2010;30:600-608.

17 Guo J, Wang L, Zhang Y, Wu J, Arpag S, Hu B, Imhof BA, Tian X, Carter BD, Suter U, Li J: Abnormal junctions and permeability of myelin in PMP22-deficient nerves. Ann Neurol 2014;75:255-265.

18 Sereda M, Griffiths I, Puhlhofer A, Stewart H, Rossner MJ, Zimmerman F, Magyar JP, Schneider A, Hund E, Meinck HM, Suter U, Nave KA: A transgenic rat model of Charcot-Marie-Tooth disease. Neuron 1996;16:1049-1060.

19 Chan CE, Odde DJ: Traction dynamics of filopodia on compliant substrates. Science 2008;322:1687-1691.

-20 Stukel JM, Willits RK: Mechanotransduction of Neural Cells Through Cell-Substrate Interactions. Tissue Eng Part B Rev 2016;22:173-182.

-21 Spedden E, White JD, Naumova EN, Kaplan DL, Staii C: Elasticity maps of living neurons measured by combined fluorescence and atomic force microscopy. Biophys J 2012;103:868-877.

22 Serinagaoglu Y, Pare J, Giovannini M, Cao X: Nf2-Yap signaling controls the expansion of DRG progenitors and glia during DRG development. Dev Biol 2015;398:97-109.

-23 Rosso G, Young P, Shahin V: Implications of Schwann Cells Biomechanics and Mechanosensitivity for Peripheral Nervous System Physiology and Pathophysiology. Front Mol Neurosci 2017;doi: 10.3389/ fnmol.2017.00345:

24 Rosso G, Liashkovich I, Young P, Shahin V: Nano-scale biophysical and structural investigations on intact and neuropathic nerve fibers by simultaneous combination of atomic force and confocal microscopy. Front Mol Neurosci 2017; doi.org/10.3389/fnmol.2017.00277:

25 Nodari A, Zambroni D, Quattrini A, Court FA, D’Urso A, Recchia A, Tybulewicz VL, Wrabetz L, Feltri ML: Beta1 integrin activates Rac1 in Schwann cells to generate radial lamellae during axonal sorting and myelination. J Cell Biol 2007;177:1063-1075.

26 Pankov R, Endo Y, Even-Ram S, Araki M, Clark K, Cukierman E, Matsumoto K, Yamada KM: A Rac switch regulates random versus directionally persistent cell migration. J Cell Biol 2005;170:793-802. 